\title{
Unity in Diversity? Polarization, Issue Diversity and Satisfaction with Democracy
}

\author{
JULIAN HOERNER ${ }^{* 1}$ AND SARA B. HobOLT ${ }^{\dagger 1}$ \\ ${ }^{1}$ London School of Economics and Political Science
}

September 16, 2019

\begin{abstract}
How do the range of issues voters care about and party system polarization impact democratic outcomes? Recent debates have focused on the negative effect of polarized systems on democratic quality. However, the extent to which this polarization is channeled or diffused over a wide range of issues on the public agenda has not been analyzed systematically. Using data from 31 European countries from 2003-2018, we show that party polarization indeed has a negative effect on people's satisfaction with democracy. Importantly, however, we demonstrate that at high levels of issue diversity, measured as the distribution of responses to the 'Most Important Issue' item, the negative effect of polarization is minimized. Drawing on the deliberative democracy literature, we argue that at low levels of issue diversity, polarization makes compromise in society less likely and the political discourse more antagonistic. However, at higher levels of issue diversity, contestation and conflict can be diffused over a large range of issues, providing more favourable conditions for collective will formation and, ultimately, higher levels of satisfaction with democracy.
\end{abstract}

*J.M.Hoerner@lse.ac.uk

†S.B.Hobolt@lse.ac.uk 


\section{Introduction}

In recent years, party polarization has attracted significant scholarly and media attention. Some authors argue that polarization has made bipartisan cooperation more difficult (Linde and Ekman, 2003; Ezrow and Xezonakis, 2011). Concerns have been raised that party polarization leads to a more antagonistic behaviour against opposing partisans (Iyengar and Westwood, 2015; Mason, 2015) and to more uncivil political disocurse (Gervais, 2016). Party polarization has thus been seen to have a negative effect on a number of indicators of the quality of democratic regimes. However, focusing on polarization alone misses an important element of political change in Western societies. Our argument is that issue diversity - or the extent to which voters agree on which is the most important political issue at a given moment (McCombs and Zhu, 1995; Edy and Meirick, 2018) - is an important conditioning factor which shapes the impact of party system polarization on satisfaction with democracy, and one which has been largely overlooked. The concept of issue diversity has been employed to analyze the relationship between public opinion and the breath of topics covered party leaders' rhetoric (Hobolt and Klemmensen, 2008) and party manifestos (Greene, 2016) as well as the electoral success of incumbents and opposition parties (Greene, 2018). Moreover, it has been demonstrated that issue diversity in party platforms moderates ideological conflict in coalition negotiations and is associated with increased coalition stability (Greene, 2017).

Our contribution is to demonstrate that the effect of party system polarization on satisfaction with democracy is moderated by the level of issue diversity in the electorate. In other words, the negative effect of party polarization is less pronounced when the public is concerned with a wide range of issues. We test our argument by combining Eurobarometer data from 31 European countries covering the period from 2003 to 2018 with data from the Comparative Manifestos Project (CMP) on party system polarization. The results from our analysis demonstrate that at low levels of issue diversity, party system polarization has a negative effect on satisfaction with democracy, at both the domestic and EU level, but this negative effect diminishes at higher levels of issue diversity, i.e. when there is higher variance in the responses to the 'Most Important Issue' item. We find that this effect is particularly 
pronounced for respondents who occasionally or frequently engage in political discussion. This paper thus makes a significant contribution to the literature on the relationship between polarization and the quality of democracy by showing that the extent to which polarization negatively affects satisfaction with democracy crucially depends on the range of issues on the public agenda at a given point of time. This implies that we should primarily be concerned about party polarization when the public debate is concentrated on a few divisive issues. Our argument and findings speak to a long tradition in the literature postulating that democracy can be sustained under intense ideological conflict if it is not concentrated in one dimension of conflict (Dahl, 1956; Lipset, 1959).

The remainder of our paper proceeds as follows. The first section briefly reviews the literature on polarization and issue salience and introduces our expectations regarding the impact of polarization on satisfaction with democracy. The second section formulates our argument regarding the interaction of party system polarization and issue diversity, drawing on recent advances in democratic theory. The third section describes how we operationalize issue diversity empirically while the fourth section presents the results of our analysis. The final section discusses of the wider implications of our findings.

\section{Party Polarization and Issue Diversity}

The impact of party system polarization on citizens' attitudes and the quality of democratic systems is a topic of long-standing interest for political scientists (Downs, 1957; Linz, 1990). The notion of party polarization captures the extent to which parties hold diverging policy positions on the main dimension of contestation (Dalton, 2008). Particularly since the 1990s, polarization at both the level of the party system and of the electorate have received renewed scholarly attention, leading to extensive debates on whether an increase in polarization can be observed empirically (Fiorina and Pope, 2008; Abramowitz and Saunders, 2008). Party polarization has been related to a number different behavioral outcomes, often with mixed empirical evidence. For example, some studies have found that increased polarization leads to 
higher turnout due to higher-stake elections (Adams and Glasgow, 2006; Franklin, 2004), while others have argued that it leads to lower levels of electoral participation, due to the alienation of centrist voters (Hetherington, 2008; Rodon, 2017). Moreover, higher levels of polarization are associated with more hostile behaviour towards citizens with opposing political views (Iyengar and Westwood, 2015; Mason, 2015). There is also experimental evidence showing an association with less civil political discourse and debates (Gervais, 2016).

This paper focuses on one particular outcome, satisfaction with democracy, defined as '[S]ystem support at a low level of generalization. It does not refer to democracy as a set of norms but to the functioning of democracy' (Anderson and Guillory, 1997, p.70). It is a mid-range concept, which is conceptually situated between support for the government of the day and democracy as an abstract concept (ibid). The concept also provides as middle ground between Easton's (1975) concepts of diffuse support and specific support. Satisfaction with democracy is thus particularly useful for the purposes of this paper, which is concerned with attitudes towards the functioning of the democracy at a particular point in time (Anderson, 2012).

In the multilevel system of the European Union, satisfaction with democracy can be conceptualized at the domestic as well as at the supranational level. The literature has shown that perceptions of democracy at the European level are, in part, shaped perceptions of national democratic performance (Hobolt, 2012; Rohrschneider, 2002; De Vries, 2018; Anderson, 1998). Moreover polarization of party politics at the domestic level, as seen with the rise of parties on the radical right and radical left, has also been facilitated by consecutive crises at the European level (Hobolt and De Vries, 2016). Changing patterns in domestic political contestation, shaped by polarization and moderated by issue diversity, are thus likely to impact on satisfaction at both levels of government. Hence, we operationalize satisfaction with democracy both at the national and the EU level, expecting to find that the interplay between polarization and issue diversity will shape attitudes towards both levels of government.

There is a rich literature which focus on satisfaction with democracy with respect to a number of institutional factors (Anderson and Guillory, 1997), whether a person is winner or a loser in 
an election (Anderson and Listhaug, 2005; Blais and Gélineau, 2007; Singh, 2014) as well as citizen-government congruence (Kim, 2009; Reher, 2015). More recent work has explicitly focused on the impact of party level polarization, i.e. the differential between party positions, on satisfaction with democracy. A study by Ezrow and Xezonakis has shown that higher party system polarization is associated with lower levels of satisfaction (Ezrow and Xezonakis, 2011), while Xezonakis finds that it predicts lower quality of government (Xezonakis, 2012). An alternative perspective is that polarization understood as a broad range of choices in the party system has positive normative implications (Dahl, 1965; Mair, 2000; Przeworski, 2003; Anderson, 2012; Brandenburg and Johns, 2014).

The concept of party polarization thus captures the extent to which parties hold diverging views on the main ideological dimension of contestation. We argue, however, that it is not only the intensity of disagreement that is crucial, but also the extent to which that disagreement is concentrated or diffused. Does polarization capture disagreement on a single dominant issue, such as how the level of economic redistribution by the state, or is the public debate concerned with a number of overlapping and cross-cutting issue? There is an extensive literature on the conditions under which parties respond to changing issue preferences of the voters (Stimson and Erikson, 1995), how they emphasize and de-emphasize issues to get an advantage in political competition (Riker, 1993; Carmines and Stimson, 1990; Green-Pedersen, 2007) and how new parties use issues strategically to break into a party system (Hobolt and De Vries, 2015). Moreover, in terms of voters' preferences, Reher finds that turnout is higher when parties represent voters' issue concerns (Reher, 2016) and that voters whose issue concerns are represented by parties show higher levels of satisfaction with democracy (Reher, 2014). The question of issue congruence becomes especially pertinent as the issue agenda of both parties and voters arguably becomes more complex (Stecker, 2016).

Issues can be thought of not only in terms of their relative salience, but also with regard to the range of issues prominent in a political system at a given time. In this context, scholars have coined the term 'issue diversity' (McCombs and Zhu, 1995; Hobolt and Klemmensen, 2008). Issue diversity denotes the extent to which parties, or voters, care about and emphasize the 
same issue; that is, whether issue attention and emphasis is dispersed and concentrated. It is thus distinct from polarization, which refers to the extent to which voters or parties diverge on an ideological dimension. The concept of issue diversity has been applied to analyze the extent to which parties in government and opposition focus on issue sets of different size (Hobolt and Klemmensen, 2008), the durability of coalitions (Greene, 2017), differences between government and opposition parties in electoral competition (Greene, 2018) and the effects of the core functions of the executive (Jennings and Palau, 2011).

There are a number of factors which are likely drivers of varying levels of issue diversity at the level of parties and the public agenda: At the level of of the electorate itself, research has shown that the public agenda has seemingly become increasingly complex, i.e. that the public cares about greater variety of issues (Green-Pedersen, 2007) - apparently mirroring the trend of increased ideological polarization. Focusing on the US, McCombs and Zhu found a secular trend of increasing issue or agenda diversity, both in terms of the absolute number of issues on the political agenda and the extent to which citizens perceive different issues as most important. Their work focused on description, but did stipulate that the expansion of education is causing this phenomenon by (McCombs and Zhu, 1995, 517). Drawing on the work of Mayer, they discuss that generational replacement, social and demographic change such as increasing ethnic diversity, external events and and media effects might play an important role in determining issue diversity (McCombs and Zhu, 1995, 517). Arguably, the same factors which influence the level of issue diversity might also influence polarization at the party level. For example, external events such as the financial crisis or the Syrian Refugee crisis which led to a steep decline in issue diversity (as shown in Figure 3) are also likely to have influenced levels of party system polarization. Moreover, changing media patterns might also have an impact on party system polarization (Tucker and Nyhan, 2018). The relationship between issue diversity and polarization is thus complex and multidimensional.

But what is the impact of issue diversity at the electoral level? We remain agnostic with regard to the impact of issue diversity on our variable of interest, satisfaction with democracy. However, we argue that the issue diversity can play a role in moderating the effect of ideological 
polarization on satisfaction with democracy. Previous research has shown that, in the context of coalition negotiations, parties with ideological divergent positions find it easier to reach an agreement and remain in a coalition for longer if they negotiate their agreement over a broader range of issues (Greene, 2016). Similarly, we argue that among citizens the negative effect polarized party systems on satisfaction with democracy could be ameliorated by a fragmented issue agenda. To elaborate on this argument, we present the notion of 'diffused polarization' which draws on concepts from the literature on deliberative democracy, as explained in the next section

\section{Deliberation and Diffused Polarization}

How does the diversity of the issue agenda moderate the effect of polarization on satisfaction with democracy? To answer this question, we draw on the literature on deliberative democracy (e.g. Habermas, 1992; Cohen, 1989), which has been burgeoning in the last decades in the field of democratic theory, but has only rarely been applied to the empirical literature in the field of political behavior, with the exception of a growing body of work on deliberative polling (e.g. Andersen and Hansen, 2007; Luskin and Jowell, 2002). The theory of deliberative democracy is particularly useful in understanding the agenda- and will formation stage of the democratic process. Warren (2017) distinguishes between three core functions that a political system has to fulfill in order to count as democratic: empowered inclusion, i.e. ensuring that all actors which should be enfranchised are taken into account, collective agenda and will formation and collective decision-making, or the aggregation of preferences into collective agents capable of doing collective things (p. 43). For the purposes of this paper, the second function is the most relevant. It addresses the question of 'how [citizens] enter into relationships of understanding with others, such as that they can identify and understand their preferences, and relate their preferences to others and to collective agendas' (ibid.). Warren argues that democratic practice which is best suited to serve this function is deliberation (p. 49).

We understand deliberation as the 'offering and receiving of cognitively compelling reasons 
about a common concern' (Warren, 2017, p.47). In practical terms, this process is likely to take place in the form of discussions about political issues with other voters. Arguably, this suggests that the impact of polarization on the 'quality' of a democratic system - and the citizens' perception thereof - is strongest with regard to the function of agenda and will formation which requires deliberative practices. Even though not necessarily aimed at consensus, deliberation requires commitment to minimum levels of respect, common good orientation and sincerity (Baechtinger and Warren, 2017, p.5) which are arguably difficult to achieve when polarization is high. Political discussion becomes more confrontational. Deliberation, even in forums which have been specifically designed for the purpose goal-oriented deliberation can be challenging for the participants (Thompson and Hoggett, 2001). It is likely to become even more so when perceptions of supporters of the political opponent are charged negatively (e.g. Mason, 2015), which is arguably more likely when polarization is concentrated along a small number of issue dimensions.

The extent to which deliberative practices, and thus collectives will formation, are functional in highly polarized publics might thus be limited. Political discussion becomes less convivial and productive. Indeed, deliberation could even lead to further polarization in this context (Wojcieszak, 2012). With the collective will formation stage of the democratic process hampered, overall satisfaction with the current state of democracy in the polity is likely to decrease. We thus formulate the following hypothesis:

\section{H1: High levels of party system polarization are associated with low levels of satisfaction} with democracy.

However, it is not only polarization itself that can impact the collective will formation process through deliberation, but also the extent to which disagreement is channeled or diffused over a number of aspects. We would thus expect that the impact of polarization on the quality of the democratic process at the public will formation stage is moderated by issue diversity - or the extent to which voters perceive the same or different issues as most important. As mentioned above, Greene finds that an increase in issue diversity is associated with more negotiation success and coalition survival, even in the case of ideological heterogeneous 
coalitions (Greene, 2017). We believe that this general logic also applies to the level of the mass public.

In so doing, we follow the approach of Mansbridge and Martí (2010), who propose 'deliberative negotiation' as an extension of the deliberative ideal (p. 69). We are particularly interested in what Mansbridge calls integrated solutions, in which a win-win solution emerges as the participants value different aspects or issues differently (p. 71). Indeed, experimental evidence from the social psychology literature suggests that compromise is more likely when the negotiations take place over a variety of issues (Van der Schalk, J., Beersma, B. and De Dreu, 2010). In this context, the concept of "negotiation" does not refer to bargaining over a defined price, but rather as a more general exchange of "interests or opinions on what is good for the polity", as often takes place in political discussion (Mansbridge and Martí, 2010, p.70). Our argument suggests that higher levels of issue diversity increase subjective perceptions of the state of democracy by diffusing the antagonizing effects of high levels of polarization. In terms of the psychological processes that underlie the reactions of individual voters in a polarized polity when confronted with higher levels of issue diversity, we argue that the quality and nature of actual conversations about politics play a very important role. Arguably, these are situations in which polarization manifests itself concretely, as discussions are likely to become more confrontational, antagonistic and unpleasant. We suggest that voters then infer the state of democracy in the country at large from the quality of these discussions they experience in a their everyday lives. We thus formulate the following hypothesis:

H2: The negative effect of party system polarization on satisfaction with democracy is weaker at higher levels of issue diversity.

If the underlying mechanism that links party polarization and issue diversity with satisfaction with democracy concerns the nature of deliberation, individual variation in the extent to which citizens engage in actual political debate can provide us with a better handle on that mechanism. As we hypothesize that polarization has a negative effect on satisfaction with democracy by disturbing a deliberative process, and that this effect is moderated by issue diversity, we expect the compensating effect of issue diversity to be most pronounced for 
individuals who frequently engage in political discussion. In other words, people who discuss political issues frequently should see the biggest improvement in satisfaction with democracy as the negative effects of polarization are diffused by higher issue diversity. The rationale here is they receive a stronger 'treatment' through which the state of polarization and issue diversity in society is revealed to them - they have more information about the actual levels of issue diversity and polarization and thus update their assessment of the quality of democracy in a country more extensively. Thus, we hypothesize:

\section{H3: The moderating effect of issue diversity on the relationship between polarization and satisfaction with democracy is more pronounced for individuals who frequently discuss politics.}

Having established our expectations about the moderating effect of issue diversity on the effect of party polarization as well as the mechanism at the individual level in the form of the frequency of political discussion, we can think about different combinations of polarization and issue diversity at the system level. These combination can be described as stylized ideal types in the form of four scenarios. The first scenario combines high party system polarization with low issue diversity - i.e. voters perceive the same issue as most important and parties are highly polarized ideologically. The potential for confrontation thus cannot be diffused across a variety of issues. We term this scenario an 'antagonistic public'. This was for example the case in Greece during the years of the financial crisis, when the issue of the economy dominated the agenda, but society was highly polarized ideologically. The second scenario relates to a situation in which both polarization and issue diversity are high. This configuration allows for a diffusion of polarization and might thus provide more favourable conditions for collective will formation through deliberation in a 'diffused public'. Examples here include a country such as Denmark, which is characterized by a polarized party system, but also by a diverse public issue agenda.

Two further combinations of polarization and issue diversity are possible. A scenario in which both polarization and issue diversity are low would constitute a 'consensual public': citizens care about the same issue and parties are close to each other ideologically. Germany fits this 
definition for much of the 2000s and the early 2010s, when the economic performance of the country and unemployment were clearly seen as most important issues, but the public was generally in consensus. Finally, we can think of a scenario in which polarization is low, but issue diversity is high - a situation in which conflict should be limited. We term this scenario a 'compartmentalized public'. An example here would be the United Kingdom under New Labour, a time characterized by broad ideological agreement and a diverse issue agenda. The four different combinations are visualized in Table 1.

Figure 1: Four Types of Publics as the Results of the Interaction of Polarization and Issue Diversity

\begin{tabular}{|l|l|l|}
\hline & Low Issue Diversity & High Issue Diversity \\
\hline Low Polarization & $\begin{array}{l}\text { Consensual Public } \\
\text { Voters care about the same } \\
\text { issues and agree }\end{array}$ & $\begin{array}{l}\text { Compartmentalized Public } \\
\text { Voters care about a variety of issues } \\
\text { and agree }\end{array}$ \\
\hline High Polarization & $\begin{array}{l}\text { Antagonistic Public } \\
\text { Voters care about the same } \\
\text { issues and disagree }\end{array}$ & $\begin{array}{l}\text { Doters care about a variety of issues } \\
\text { and disagree }\end{array}$ \\
\hline
\end{tabular}

In the next section, we discuss how we test the effect of polarization and issue diversity on satisfaction with democracy. 


\section{Methods and Measurement}

Issue diversity denotes the extent to which voters agree or disagree on what is the most important issue at a given point of time. Numerous indices have been developed to measure how observations are distributed among different categorical groups in a dataset, often originating in ecology to measure the abundance of different types of species, but have been adopted to various disciplines such as economics, finance and communication studies (Tabner, 2007). As mentioned above, the concept has been taken up in political science more recently and has received growing attention (McCombs and Zhu, 1995; Hobolt and Klemmensen, 2008; Boydstun and Thomas, 2014; Greene, 2016).

To measure issue diversity at the level of voters, we rely on the 'Most Important Issue' item from the Eurobarometer surveys. ${ }^{1}$ Since this measure might not be immediately intuitive, consider the following stylistic representation:

\footnotetext{
${ }^{1}$ See Appendix A for a detailed description of the measure
} 
Figure 2: Low and High Issue Diversity
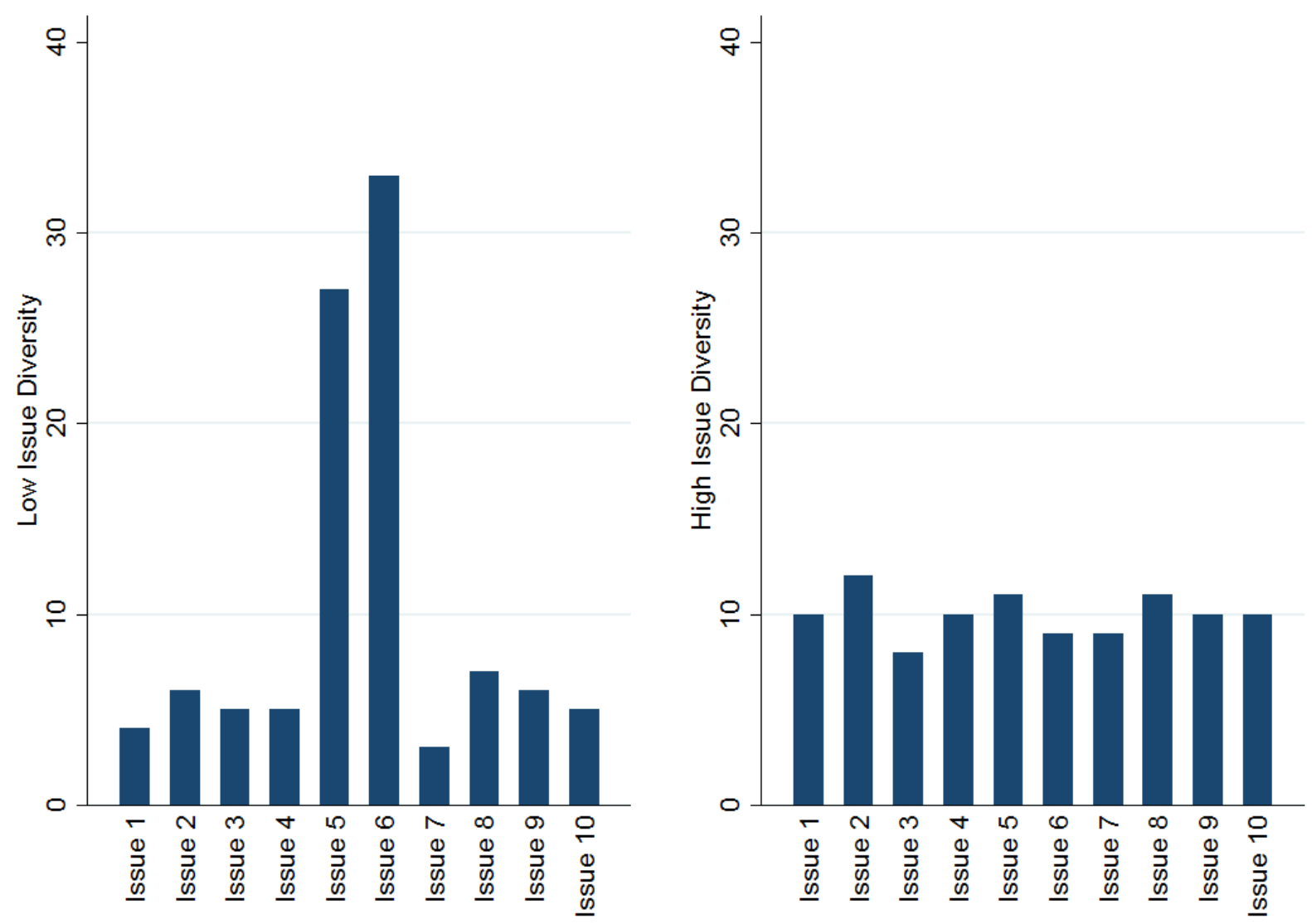

As Figure 2 shows, in a scenario of low issue diversity, there are one or two issue categories which have been mentioned by many respondents, whereas few respondents mentioned the other categories (the panel on the left). By contrast, in a scenario of high issue diversity, the respondents mention all issue categories more with more or less equal frequency (the panel on the right). We use the Herfindahl-Hirschmann Index (also known as the Simpson Index). ${ }^{2}$ In the formula below, $s$ denotes the proportion of responses indicating issue $i$ as the most important one as the share of all responses and $N$ is the total number of issues in the study. As respondents are asked to indicate up to two issues as the most important one, the number of responses rather than the number of respondents indicating a category as the most important one is used as the unit of analysis (Edy and Meirick, 2018, p.667).

\footnotetext{
${ }^{2}$ in Appendix C, Table SI7, we display the results for the Shannon entropy metric with substantially similar results.
} 


$$
H H I=1-\sum_{i=1}^{N} s_{i}^{2}
$$

This value was calculated per country for each Eurobarometer survey. We use the reverse of the original Herfindahl-Hirschmann Index so that higher values indicate more issue diversity. There are a number of other indices that capture the diversity of categorical variables (Boydstun and Thomas, 2014).

We measure party system polarization using data from the Comparative Manifestos Project (CMP). To calculate an index of polarization, we rely on the left-right "RILE" score and follow the operationalization of party system polarization by Dalton (Dalton, 2008) ${ }^{3}$. We use linear interpolation for Eurobarometer surveys which took place in years between elections and are therefore not covered by the CMP. ${ }^{4}$ The development of Issue Diversity and Polarization over time are displayed in Figure 3 below:

\footnotetext{
${ }^{3} \mathrm{pol}=\sqrt{\sum_{i=1}^{N}\left(\left(\frac{\left(p_{i}-\text { wmean } 0\right.}{100}\right)^{2} V_{i}\right)}$, where $p o l$ is the polarization index ranging from 0 to $10, p$ is a party $i$ 's left-right
} position and V is a party's vote share, and wmean is the weighted mean of all parties' positions. Here we use the CMP 'rile' score as a measure of parties' left-right positions $p$, which is an aggregate measure based on the categorization of quasi-sentences in a number of policy categories (see Budge, 2001)

${ }^{4}$ As an alternative measure of polarization at the party level, we run a model using party positions from the Chapel Hill Expert Survey (CHES), to be found in Appendix C (Table SI9). 
Figure 3: Issue Diversity and Polarization over Time and across Countries
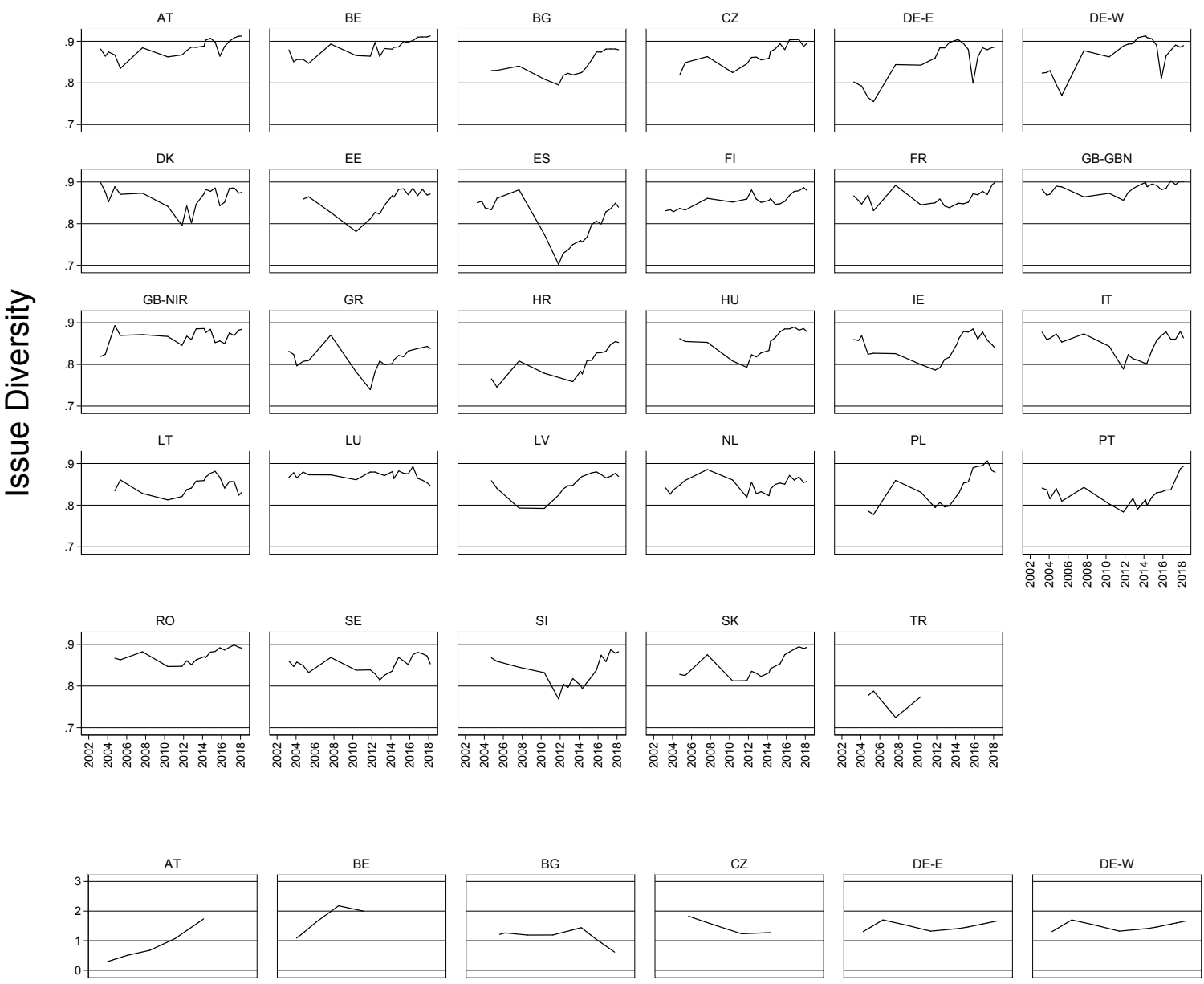

ES
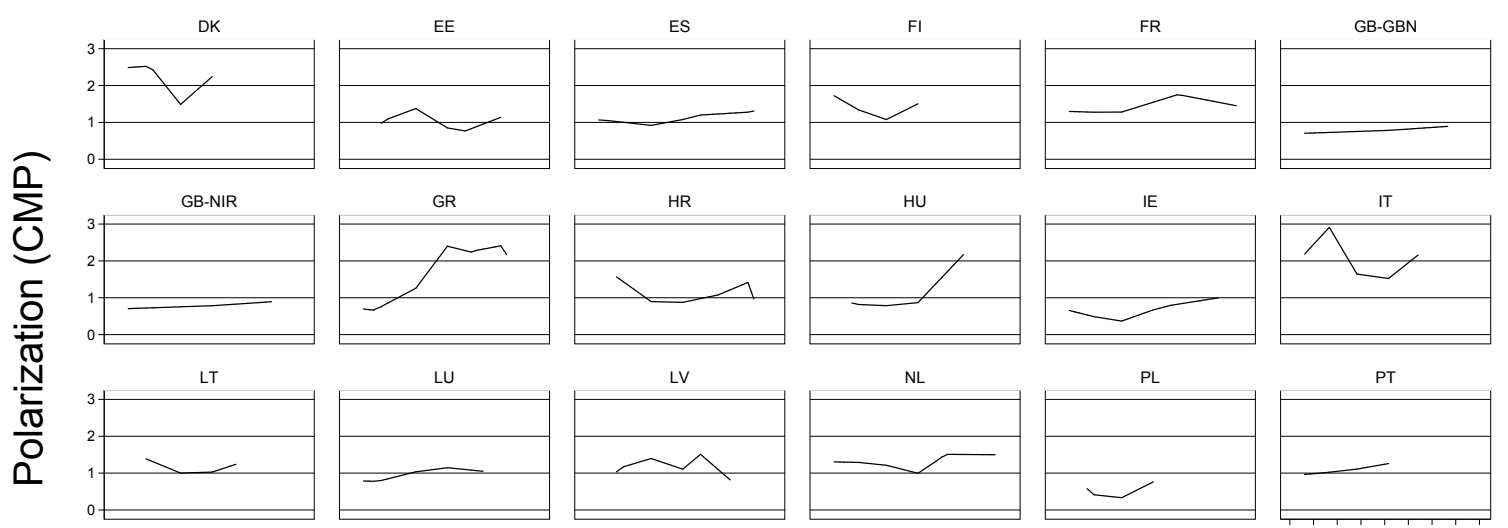

LV

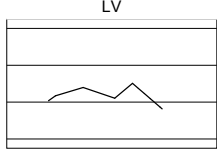

NL
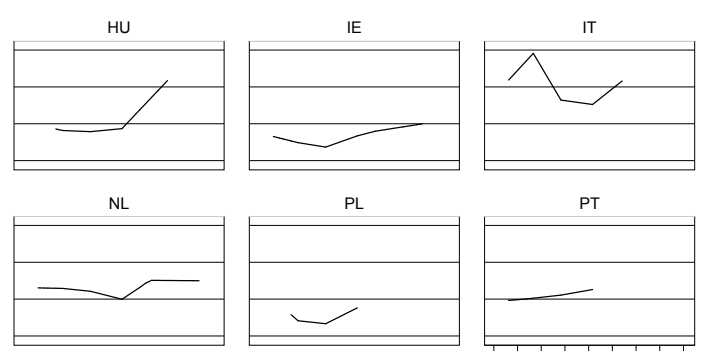

PT

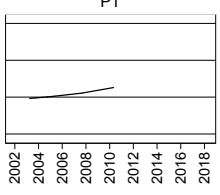

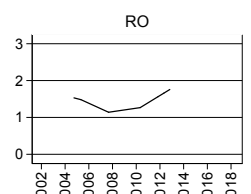

SE

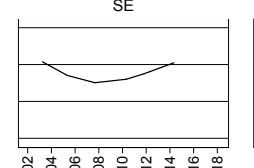

SI
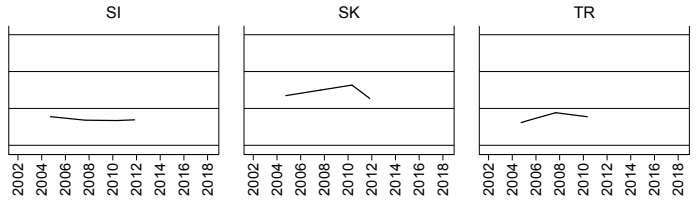
As Figure 3 shows, there is significant cross-country and over-time variation with regard to both issue diversity and polarization. A significant drop in issue diversity occurred in several countries at the time of the financial crisis, when economic issues dominated the public agenda. Unsurprisingly, countries which were particularly strongly affected by the crisis and subsequent austerity measures such as Greece and Spain saw the strongest decline, and continue to display comparatively low levels of issue diversity. Likewise, temporary drops in issue diversity can observed when exogenous events come to dominate the public agenda - a notable drop in issue diversity in Germany in 2015 at the height of the Refugee Crisis being a prime example. However, generally issue diversity is high in Northern Europe, comparatively lower in Southern Europe and increasing in the post-Communist Societies of Central and Eastern Europe. Turning to polarization at the party level, variation between countries and over time is perhaps even more striking. Some countries, notable Austria, Greece and Hungary saw a clear increase in party-system polarization, driven by the presence of extreme parties at different ends of the ideological spectrum. The patterns of issue diversity and polarization thus mirror recent political and societal developments and events. Finally, it is important to point out that while issue diversity and polarization theoretically not necessarily independent, we find only a small a negative correlation of -0.0153 between the two in our dataset.

For our dependent variable, satisfaction with democracy, we rely on an item from the Eurobarometer allowing respondents to rank how satisfied they are with democracy in their country from 'very satisfied' to 'not at all satisfied'. We use the inverse of this scale so that higher values indicate more satisfaction with democracy. We use two separate measures satisfaction with democracy at the national and the European level as our dependent variable. The frequency of political discussion is included as a dummy, with 0 indicating that a respondent never engages in political discussion and 1 indicating that they do so occasionally or frequently. From Eurobarometer 73.4, the question asks for engagement in political discussion on national, European and local politics. We use the measure of the national level to ensure continuity in the response. To capture a potential trend in satisfaction with democracy, we include a yearly variable. At the individual level, we control for age, gender and education and for the 
effective number of parties at the aggregate level. We then fit a a linear multilevel model with random intercepts at the country level. In Appendix C, we display four further robustness checks: a fixed effects model, an ordered logistic regression, an operationalization of issue diversity as the Shannon Entropy metric polarization operationalized as the range of party positions, all with substantially similar results. Our dataset contains around a quarter of a million observations from 28 countries for the years from 2003 until 2018. Descriptive statistics can be found in appendix A. ${ }^{5}$

\footnotetext{
${ }^{5}$ We exclude Northern Cyprus as issue categories differ.
} 


\section{Results}

As shown below, our results provide empirical support for our hypotheses that issue diversity plays an important role in moderating the effect of party polarization on satisfaction with democracy.

Table 1: Regression Results

\begin{tabular}{|c|c|c|c|c|c|c|}
\hline & Model 1 & Model 2 & Model 3 & Model 4 & Model 5 & Model 6 \\
\hline \multirow[t]{2}{*}{ Polarization $(\mathrm{P})$} & $-0.16^{*}$ & $-1.64^{*}$ & $-1.11^{*}$ & $-0.11^{*}$ & $-1.09 *$ & $-1.09^{*}$ \\
\hline & $(0.01)$ & $(0.09)$ & $(0.17)$ & $(0.01)$ & $(0.09)$ & $(0.18)$ \\
\hline \multirow[t]{2}{*}{ Issue Diversity (ID) } & $2.98^{*}$ & $0.63^{*}$ & $1.14^{*}$ & $1.80^{*}$ & 0.23 & 0.51 \\
\hline & $(0.06)$ & $(0.15)$ & $(0.26)$ & $(0.06)$ & $(0.16)$ & $(0.28)$ \\
\hline \multirow[t]{2}{*}{ Political Discussion (PD) } & $0.04^{*}$ & $0.04^{*}$ & $0.53^{*}$ & $0.04^{*}$ & $0.04^{*}$ & 0.39 \\
\hline & $(0.00)$ & $(0.00)$ & $(0.23)$ & $(0.00)$ & $(0.00)$ & $(0.24)$ \\
\hline \multirow[t]{2}{*}{ Age } & $-0.00^{*}$ & $-0.00^{*}$ & $-0.00^{*}$ & $-0.00^{*}$ & $-0.00^{*}$ & $-0.00^{*}$ \\
\hline & $(0.00)$ & $(0.00)$ & $(0.00)$ & $(0.00)$ & $(0.00)$ & $(0.00)$ \\
\hline \multirow[t]{2}{*}{ Gender } & $-0.02^{*}$ & $-0.02^{*}$ & $-0.02^{*}$ & -0.00 & -0.00 & -0.00 \\
\hline & $(0.00)$ & $(0.00)$ & $(0.00)$ & $(0.00)$ & $(0.00)$ & $(0.00)$ \\
\hline \multirow[t]{2}{*}{ Education } & $0.02^{*}$ & $0.02^{*}$ & $0.02^{*}$ & $0.01^{*}$ & $0.01^{*}$ & $0.01^{*}$ \\
\hline & $(0.00)$ & $(0.00)$ & $(0.00)$ & $(0.00)$ & $(0.00)$ & $(0.00)$ \\
\hline \multirow[t]{2}{*}{ ENEP } & $-0.05^{*}$ & $-0.06^{*}$ & $-0.06^{*}$ & $-0.05^{*}$ & $-0.05^{*}$ & $-0.05^{*}$ \\
\hline & $(0.00)$ & $(0.00)$ & $(0.00)$ & $(0.00)$ & $(0.00)$ & $(0.00)$ \\
\hline \multirow[t]{2}{*}{ Year } & $-0.02^{*}$ & $-0.02^{*}$ & $-0.02^{*}$ & $-0.01^{*}$ & $-0.01^{*}$ & $-0.01^{*}$ \\
\hline & $(0.00)$ & $(0.00)$ & $(0.00)$ & $(0.00)$ & $(0.00)$ & $(0.00)$ \\
\hline \multirow[t]{2}{*}{ Px ID } & & $1.78^{*}$ & $1.13^{*}$ & & $1.18^{*}$ & $1.18^{*}$ \\
\hline & & $(0.11)$ & $(0.20)$ & & $(0.11)$ & $(0.21)$ \\
\hline \multirow[t]{2}{*}{$\mathrm{P} \times \mathrm{PD}$} & & & $-0.65^{*}$ & & & -0.03 \\
\hline & & & $(0.18)$ & & & $(0.19)$ \\
\hline \multirow[t]{2}{*}{ ID $x$ PD } & & & $-0.61^{*}$ & & & -0.39 \\
\hline & & & $(0.28)$ & & & $(0.29)$ \\
\hline \multirow[t]{2}{*}{$\mathrm{P} \times \mathrm{ID} \times \mathrm{PD}$} & & & $0.79^{*}$ & & & 0.02 \\
\hline & & & $(0.21)$ & & & $(0.22)$ \\
\hline \multirow[t]{2}{*}{ Constant } & $32.08^{*}$ & $33.97^{*}$ & $33.71^{*}$ & $24.60^{*}$ & $25.89^{*}$ & $25.55^{*}$ \\
\hline & $(0.82)$ & $(0.83)$ & $(0.85)$ & $(0.84)$ & $(0.85)$ & $(0.87)$ \\
\hline Number of Groups & 31 & 31 & 31 & 31 & 31 & 31 \\
\hline Observations & 286503 & 286503 & 286503 & 250977 & 250977 & 250977 \\
\hline
\end{tabular}

Table 1: Results of a liner multilevel model with random intercepts at the level of countries. ${ }^{*} p<0.05$ 
Model 1 (Table 1) shows, as expected, that the main effect of party system polarization on satisfaction with democracy is negative. Substantially, a full scale increase of party system polarization would be associated with a decrease of around 16 per cent in satisfaction with democracy. The effect would thus be similar in size to the change induced by a respondent adjusting the economic expectations for their household from 'improving' to 'getting worse' (see Table SI Table SI in Appendix C). A full increase in issue diversity would is associated with a 30 per cent increase in satisfaction with democracy. We find an analogous, if slightly weaker effect with regard to satisfaction with democracy in the EU (Model 4). These findings are in line with our expectations: higher levels of polarization are likely to make the deliberative act of collective will and agenda formation more difficult, reducing satisfaction with democracy (H1). Moreover, we find a positive main effect for issue diversity. The high diffusion of the issue space could improve the climate for deliberation at the will formation stage.

Figure 4: Effect of Electoral Polarization on Satisfaction with Democracy at different Levels of Issue Diversity

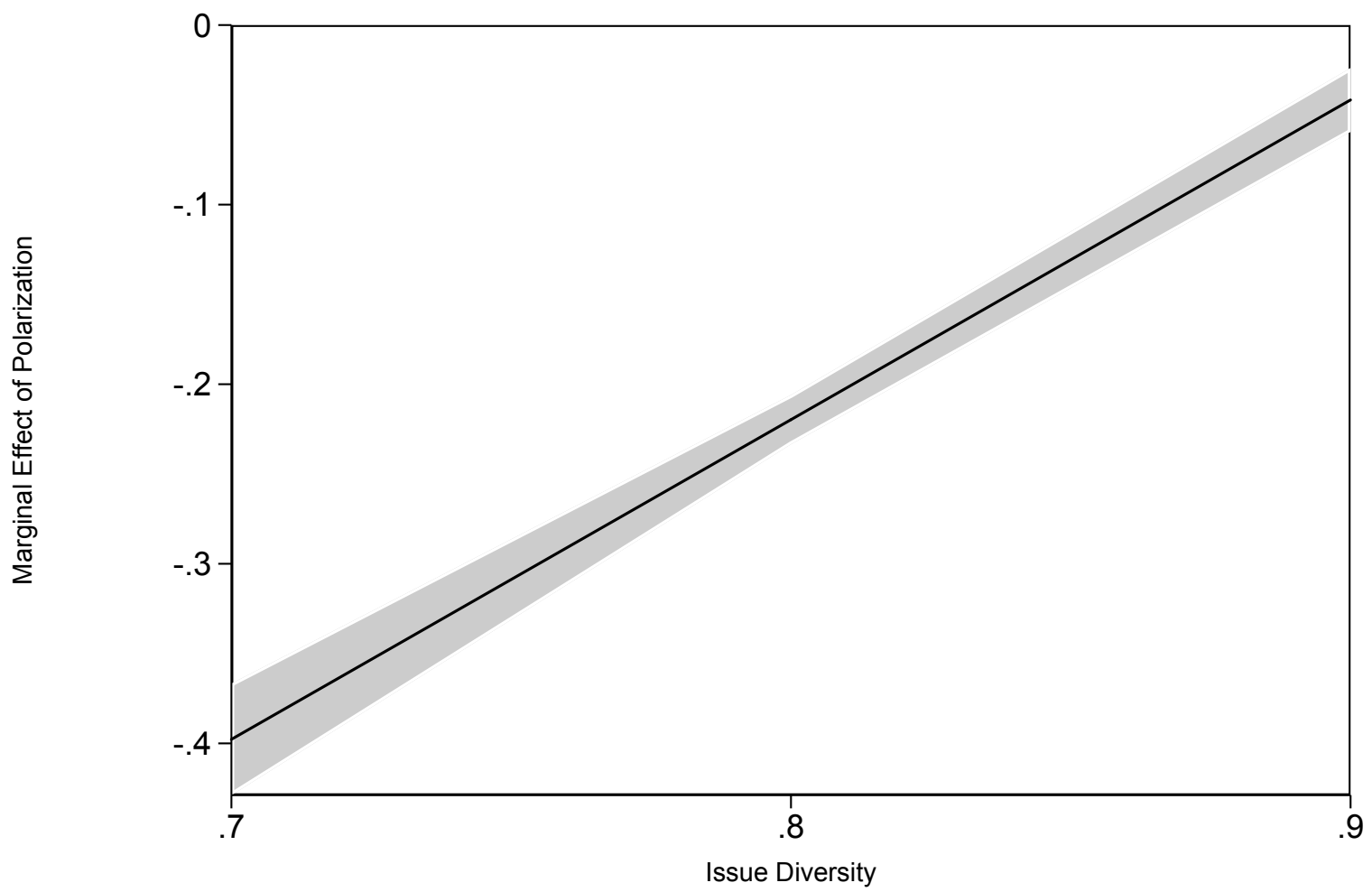


In line with our main argument, Figure 4 shows that the effect of party system polarization is negative across all levels of issue diversity, but its size decreases as issue diversity increases. In other words, the negative impact of polarization on satisfaction with democracy gets weaker as the issue preferences of the public become more diverse (Model 2). We find a similar effect at the European level (Model 5). Our findings provide support for the argument that 'diffused polarization' has less of a negative impact on satisfaction with democracy (H2). Substantively, this implies that in a country like Greece in 2011 with an issue diversity score of around 0.7 , an increase of party system polarization by one standard deviation is associated with a decrease of a citizens' satisfaction with democracy by 7.5 per cent (around the same size as the effect of a respondent adjusting their economic expectations for their household from staying the same to getting worse). By contrast, at high levels of issue diversity of 0.89 , for example in Germany in 2012, the same increase in polarization would only lead to a 0.8 per cent decrease in satisfaction with democracy. Arguably, the fact that citizens perceive different issues to be most important increases the chances for successful collective will formation and deliberation by providing the potential for compromise and 'partly integrative solutions' (Warren and Mansbridge, 2013). Figure 5 plots the level of satisfaction with democracy at different levels of polarization and issue diversity.

Figure 5: Predicted values of Satisfaction with Democracy at different values of polarization and issue diversity

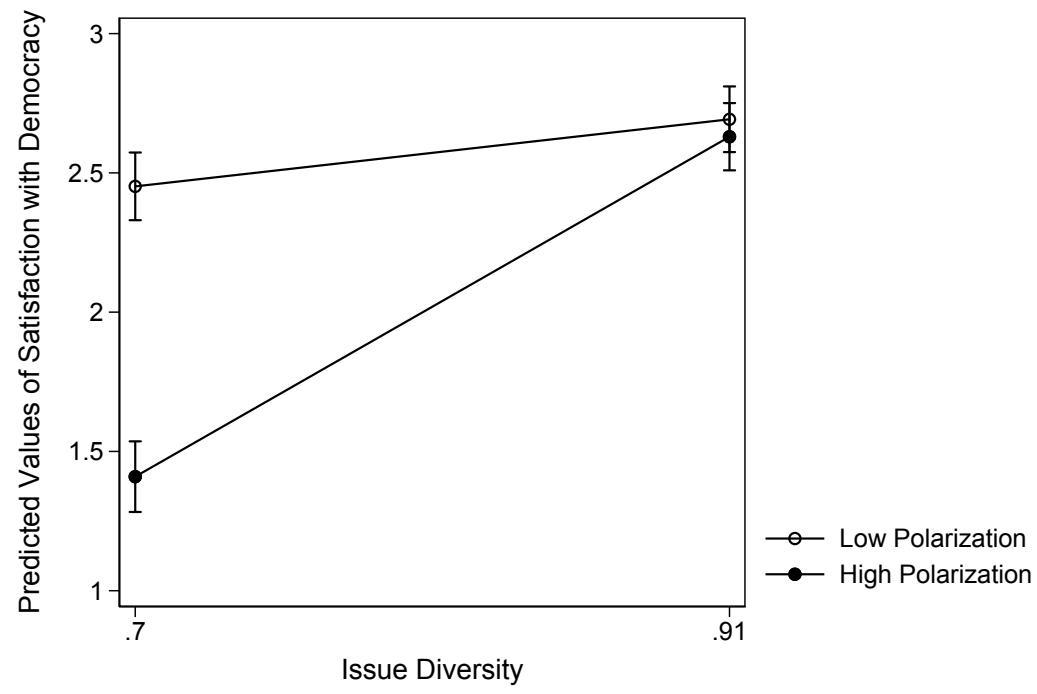


In Figure 1, we presented a 'model of four publics' depicting four different ideal type combinations of levels of issue diversity and polarization. In Figure 5, we demonstrate these 'four publics' empirically. The predicted values show that publics with low levels of polarization at both low and high levels of issue diversity are associated with high levels of satisfaction with democracy. There is only a very small and insignificant difference between the levels of satisfaction in 'consensusal' and 'compartmentalized' publics. In contrast, low issue diversity combined with high polarization ('antagonistic public') is associated with low levels of satisfaction with democracy. However, in line with our argument, we find that the combination of high issue diversity and high polarization is associated with high levels of satisfaction with democracy. Indeed 'diffused' publics show the same level of satisfaction with democracy as 'compartmentalized' publics. Our results thus show that the combination of high issue diversity and high polarization is associated with high levels of satisfaction with democracy. This suggests that the interplay between polarization and issue diversity plays a role in shaping levels of satisfaction with democracy, and that analyzing the effect of the former in isolation would mean missing an important part of the story.

Next, we investigate the moderating effect of how often an individual engages in political debates. Recall our proposed mechanism: we argue that polarization hinders deliberative processes of collective will formation, but that this is moderated by issue diversity - when issue diversity is low and polarization is high, antagonistic contestation over a limited number of issues is associated with low levels of satisfaction with democracy. High levels of issue diversity facilitate deliberation even under conditions of high polarization. At the individual level, we thus expect that the negative effect of polarization on satisfaction with democracy is most pronounced for individuals who frequently engage in political discussion. We plot the relationship between polarization, issue diversity and frequency of political discussion as a three-way interaction in Figure 6. 
Figure 6: Marginal Effect of Party Polarization on Satisfaction with Democracy at different levels of Issue Diversity and Political Discussion

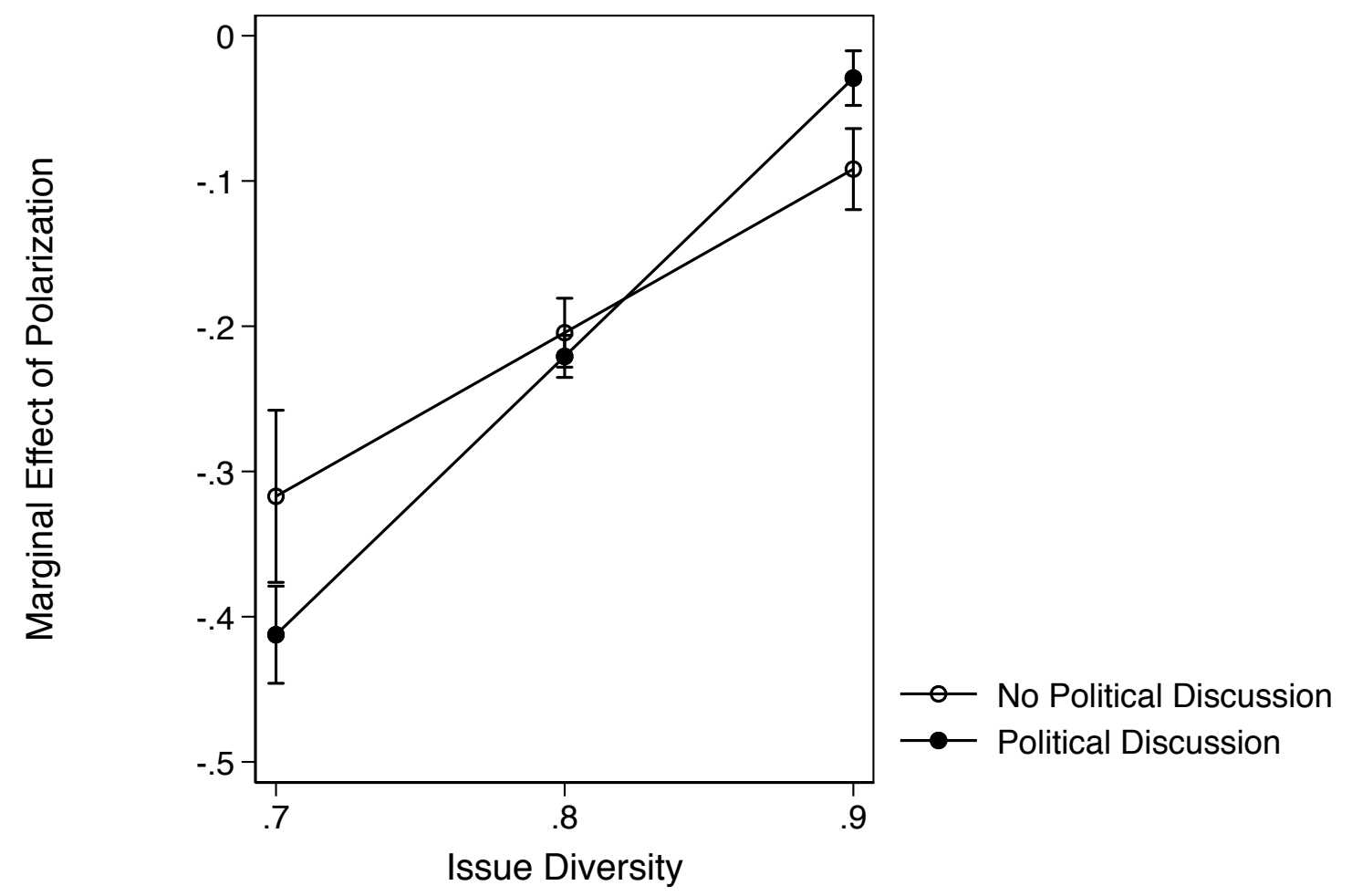

As Figure 6 shows, at the lowest level of issue diversity, the negative effect of a one-unit increase in polarization is around 25 per cent larger for respondents who occasionally or frequently engage in political discussion compared who those who never do so (Model 3). In line with our argument, polarization is thus likely to have a negative effect on satisfaction with democracy by hampering the potential for successful political discussion as a deliberative act. At the highest level of issue diversity, the negative effect for respondents who engage in political discussion is only a third as strong as for those who do not. Thus, the moderating impact of issue diversity on the effect of polarization on satisfaction with democracy seems to be particularly pronounced for respondents who engage more often in political discussion, in line with Hypothesis 3. This finding lends further support to our argument that issue diversity ameliorates the negative effect of polarization by weakening its impact on political discussion and a form of collective will formation and deliberation. Interestingly, the effect for 
this three-way interaction is not significant for satisfaction with democracy at the European level. Potentially, this indicates that deliberative mechanisms play a less important role in generating satisfaction with democracy in the EU due to its lower salience compared to domestic politics.

\section{Conclusion}

This study presents the idea of 'diffused polarization', according to which the impact of party system polarization is contingent on the level of issue diversity of the public - the extent to which voters care about a narrow or wide set of issues. Our argument starts from the premise that agenda and will formation is crucial to the democratic process (Warren, 2017). High levels of polarization are likely to disrupt this process, as several preconditions for successful deliberation might be absent in this context and the public becomes 'antagonistic' and political discussion between voters is hindered. However, the negative impact of polarization can be diffused if the public cares about a wide range of issues so that room for bargaining, compromise and 'partly integrative solutions' is given (Mansbridge and Martí, 2010).

The findings from our analysis of satisfaction with democracy in 31 European countries between 2003 and 2018 support our argument show that while party system polarization has a negative effect on satisfaction with democracy, the magnitude of this effect decreases at higher levels of issue diversity. We consider this as evidence in support of our diffused polarization model: when polarized politics is diffused across a number of issues it is less harmful for democratic deliberation. As expected, this effect is strongest for respondents who frequently engage in political discussion. However, issues of causality remain: It is plausible that individuals who are dissatisfied with the state of democracy are more like to vote for extreme parties who further polarize the system.

Nevertheless, we believe that this study makes an important contribution to debates on the effect of polarization on the quality of democracy, which has become a pertinent topic in the light of recent political developments around the world. Our findings speak to a growing 
literature which states that polarization is a complex phenomenon which is most harmful if it does away with cross-cutting identities and preferences (Iyengar and Westwood, 2015; Mason, 2015). The most dangerous form of polarization is that which presents itself as a single dimension of conflict that divides people into two antagonistic groups. As Lipset wrote: 'inherent in all democratic systems is the constant threat that the group conflicts which are democracy's lifeblood may solidify to the point where they threaten to disintegrate society' (Lipset, 1959, 83). Our findings suggest that we can be less concerned with an increase in ideological polarization if it manifests itself across a number of cross-cutting issues. Future research could study how the emergence of new salient issues, such as immigration and Euroskepticism, influence the effect of party polarization on satisfaction with democracy. Moreover, studies could test the interaction of polarization and issue diversity and their impact on satisfaction with democracy experimentally or in focus groups and citizens' assemblies to better examine the precise mechanisms through which they impact political discussion. The findings in this paper makes an important first contribution to the literature on party system polarization by highlighting that its negative effects can be diffused at high levels of issue diversity. 


\section{References}

Abramowitz, A. and L. Saunders. 2008. "Is polarization a myth?" The Journal of Politics $70(2): 542-555$.

Adams, J., Clark, M., Ezrow, L. and G. Glasgow. 2006. "Are niche parties fundamentally different from mainstream parties? The causes and the electoral consequences of Western European parties' policy shifts, 1976-1998." American Journal of Political Science 50(3):513-529.

Andersen, V. and K. Hansen. 2007. "How deliberation makes better citizens: The Danish Deliberative Poll on the euro.” European Journal of Political Research 46(4):531-556.

Anderson, C. 1998. "When in doubt, use proxies: Attitudes toward domestic politics and support for European integration." Comparative political studies 31(5):569-601.

Anderson, C. 2012. How Electoral Systems Shape What Voters Think About Democracy. In conference on 'Duty and Choice: Participation and Preferences in Democratic Elections'.

Anderson, C., Blais, A., Bowler, S., Donovan T. and O. Listhaug. 2005. Winning Isn't Everything: Losers' Consent and Democratic Legitimacy. In Losers' Consent: Elections and Democratic Legitimacy, ed. S. Bowler T. Donovan C. Anderson, A. Blais and O. Listhaug.

Anderson, C. and C. Guillory. 1997. "Political institutions and satisfaction with democracy: A cross-national analysis of consensus and majoritarian systems." American Political Science Review 91(1):66-81.

Baechtinger, A., Dryzek, J., Mansridge J. and M. Warren. 2017. Introduction. In The Oxford Handbook of Deliberative Democracy, ed. J. Mansbridge A. Baechtinger, J. Dryzek, M. Warren and B. S. Wherret.

Blais, A. and F. Gélineau. 2007. "Winning, losing and satisfaction with democracy." Political Studies 55(2):425-441.

Boydstun, A., Bevan, S. and H. Thomas. 2014. "The importance of attention diversity and how to measure it." Policy Studies Journal 42(2):173-196.

Brandenburg, H. and R. Johns. 2014. "The declining representativeness of the British party system, and why it matters." Political Studies 62(4):704-725.

Budge, I., Klingemann H. 2001. Mapping policy preferences: estimates for parties, electors, and governments, 1945-1998. Vol. 1 Oxford University Press on Demand.

Carmines, E. and J. Stimson. 1990. Issue evolution: Race and the transformation of American politics. Princeton University Press.

Cohen, J. 1989. “Deliberation and democratic legitimacy.” 1997 pp. 67-92.

Dahl, R. 1956. A preface to democratic theory. Vol. 115 University of Chicago Press.

Dahl, R. 1965. A Preface to Democratic Theory. Chicago: University of Chicago Press.

Dalton, R. 2008. "The quantity and the quality of party systems: Party system polarization, its measurement, and its consequences." Comparative Political Studies 41(7):899-920. 
De Vries, C. 2018. Euroscepticism and the future of European integration. Oxford University Press.

Downs, A. 1957. "An economic theory of political action in a democracy." Journal of Political Economy 65(2):135-150.

Easton, D. 1975. "A re-assessment of the concept of political support." British Journal of Political Science 5(4):435-457.

Edy, J. and P. Meirick. 2018. “The Fragmenting Public AgendaCapacity, Diversity, and Volatility in Responses to the 'Most Important Problem' Question.” Public Opinion Quarterly .

Ezrow, L. and G. Xezonakis. 2011. "Citizen satisfaction with democracy and parties' policy offerings.” Comparative Political Studies 44(9):1152-1178.

Fiorina, M., Abrams, S. and J. Pope. 2008. "Polarization in the American public: Misconceptions and misreadings.” The Journal of Politics 70(2):556-560.

Franklin, M. 2004. Voter turnout and the dynamics of electoral competition in established democracies since 1945. Cambridge University Press.

Gervais, B. 2016. "More than mimicry? The role of anger in uncivil reactions to elite political incivility.” International Journal of Public Opinion Research 29(3):384-405.

Green-Pedersen, C. 2007. “The growing importance of issue competition: The changing nature of party competition in Western Europe.” Political Studies 55(3):607-628.

Greene, Z. 2016. "Competing on the issues: How experience in government and economic conditions influence the scope of parties' policy messages.” Party Politics 22(6):809-822.

Greene, Z. 2017. "Working through the issues: how issue diversity and ideological disagreement influence coalition duration." European Political Science Review 9(4):561-585.

Greene, Z. 2018. "Being Heard above the Noise: The Role of Incumbent Issue Diversity in Election Campaigns.” Political Behavior pp. 1-21.

Habermas, J. 1992. "Further reflections on the public sphere." Habermas and the public sphere 428.

Hetherington, M. 2008. "Turned off or turned on? How polarization affects political engagement." Red and blue nation 2:1-33.

Hobolt, S. 2012. “Citizen satisfaction with democracy in the European Union.” JCMS: Journal of Common Market Studies 50:88-105.

Hobolt, S. and C. De Vries. 2015. "Issue entrepreneurship and multiparty competition." Comparative Political Studies 48(9):1159-1185.

Hobolt, S. and C. De Vries. 2016. "Turning against the Union? The impact of the crisis on the Eurosceptic vote in the 2014 European Parliament elections.” Electoral Studies 44:504-514.

Hobolt, S. and R. Klemmensen. 2008. “The Dynamics of Issue Diversity in Party Rhetoric.”. 
Iyengar, S. and S. Westwood. 2015. "Fear and loathing across party lines: New evidence on group polarization.” American Journal of Political Science 59(3):690-707.

Jennings, W., Bevan, S., Timmermans, A., Breeman, G., Brouard, S., Chaqués-Bonafont, L., Green-Pedersen, C., John, P., Mortensen, P. and A. Palau. 2011. "Effects of the core functions of government on the diversity of executive agendas." Comparative Political Studies 44(8):1001-1030.

Kim, M. 2009. "Cross-National Analyses of Satisfaction with Democracy and Ideological Congruence.” Journal of Elections, Public Opinion and Parties 19(1):49-72.

Linde, J. and J. Ekman. 2003. "Satisfaction with democracy: A note on a frequently used indicator in comparative politics.” European Journal of Political Research 42(3):391-408.

Linz, J. 1990. “The perils of presidentialism.” Journal of Democracy 1(1):51-69.

Lipset, S. 1959. "Some social requisites of democracy: Economic development and political legitimacy.” American Political Science Review 53(1):69-105.

Luskin, R., Fishkin, J. and R. Jowell. 2002. "Considered opinions: Deliberative polling in Britain.” British Journal of Political Science 32(3):455-487.

Mair, P. 2000. “The limited impact of Europe on national party systems." West European Politics 23(4):27-51.

Mansbridge, J., Bohman, J., Chambers, S., Estlund, D.,Føllesdal, A., Fung, A., Lafont, C., Manin, B. and J. Martí. 2010. "The place of self-interest and the role of power in deliberative democracy." Journal of political philosophy 18(1):64-100.

Mason, L. 2015. “'I disrespectfully agree': The differential effects of partisan sorting on social and issue polarization." American Journal of Political Science 59(1):128-145.

Mayer, W. 1992. The changing American mind: How and why American public opinion changed between 1960 and 1988. University of Michigan Press.

McCombs, Ma. and J. Zhu. 1995. "Capacity, diversity, and volatility of the public agenda: Trends from 1954 to 1994.” Public Opinion Quarterly 59(4):495-525.

Przeworski, A. 2003. "Freedom to choose and democracy." Economics \& Philosophy 19(2):265-279.

Reher, S. 2014. "The effect of congruence in policy priorities on electoral participation." Electoral Studies 36:158-172.

Reher, S. 2015. "Explaining cross-national variation in the relationship between priority congruence and satisfaction with democracy." European Journal of Political Research 54(1):160-181.

Reher, S. 2016. "The effects of congruence in policy priorities on satisfaction with democracy." Journal of Elections, Public Opinion and Parties 26(1):40-57.

Riker, W. 1993. Agenda formation. University of Michigan Press. 
Rodon, T. 2017. "When the kingmaker stays home: Revisiting the ideological bias on turnout." Party Politics 23(2):148-159.

Rohrschneider, R. 2002. "The democracy deficit and mass support for an EU-wide government.” American Journal of Political Science pp. 463-475.

Singh, S. 2014. "Not all election winners are equal: Satisfaction with democracy and the nature of the vote.” European Journal of Political Research 53(2):308-327.

Stecker, C.and Tausendpfund, M. 2016. "Multidimensional government-citizen congruence and satisfaction with democracy.” European Journal of Political Research 55(3):492-511.

Stimson, J., MacKuen, M. and R. Erikson. 1995. “Dynamic representation.” American Political Science Review 89(3):543-565.

Tabner, I. 2007. "A Review of Concentration, Diversity or Entropy Metrics in Economics, Finance, Ecology and Communication Science." International Journal of Interdisciplinary Social Sciences 2(4):53-60.

Thompson, S. and P. Hoggett. 2001. "The emotional dynamics of deliberative democracy." Policy \& Politics 29(3):351-364.

Tucker, J., Guess, A., Barberá, P., Vaccari, C., Siegel, A., Sanovich, S., Stukal, D. and B. Nyhan. 2018. "Social media, political polarization, and political disinformation: A review of the scientific literature.".

Van der Schalk, J., Beersma, B., Van Kleef, G. and C. De Dreu. 2010. “The more (complex), the better? The influence of epistemic motivation on integrative bargaining in complex negotiation." European Journal of Social Psychology 40(2):355-365.

Warren, M. 2017. "A problem-based approach to democratic theory." American Political Science Review 111(1):39-53.

Warren, M. and J. Mansbridge. 2013. “Deliberative negotiation.” Negotiating agreement in politics 86.

Wojcieszak, M. 2012. "On strong attitudes and group deliberation: Relationships, structure, changes, and effects.” Political Psychology 33(2):225-242.

Xezonakis, G. 2012. "Party System Polarization and Quality of Government.” QoG Working Paper Series 2012(14):14. 